\title{
Editorial
}

\section{EDITOR'S INTRODUCTION TO SPECIAL ISSUE ON BRITISH PSYCHO(-)SOCIAL STUDIES}

Psychoanalysis, Culture \& Society (2008) 13, 339-340.

doi:10.1057/pcs.2008.34

$\mathrm{F}$

or those of us outside the UK who may never have read a psychosocial study, this issue of the journal may seem to start in medias res. We will not only find ourselves in the middle of a debate about what version of psychoanalysis is best suited to study social life, but also be faced with a challenge as to the very possibility of drawing on psychoanalysis to conduct research outside the clinic. Those who have attended the annual APCS conferences have had the opportunity to hear John Bird, Simon Clarke, Paul Hoggett, Wendy Hollway, Tony Jefferson, Valerie Walkerdine and others discuss their empirical work. We hope that this issue will encourage those of our readers who do not do psychoanalytically oriented empirical research and who have not read the books and articles written by our distinguished participants in this debate - all leaders in the field of UK psychosocial studies - to explore this burgeoning field (interested readers might consult pieces previously published in JPCS and PCS, for example, Hollway and Jefferson (2002), Clarke et al. (2002), Annie Stopford (2007), as well as the special issue of the International Journal of Critical Psychology on Psycho-Social Research, Vol. 10, 2004). We also hope that those of you who do psychosocial research will submit your work to PCS so that we might, in the not too distant future, have a special issue that features actual psychoanalytic psychosocial studies.

With this issue, we say goodbye to our book review editor of 5 years, Angela Hunter, and we welcome Jason Jones as our new book review editor. Angela has worked tirelessly to introduce our readers to new and recent psychoanalytic books that examine social and cultural problems. Thank you, Angela.

\section{References}

Clarke, S., Figlio, K. and Bird, J. (2002). Cultural Marxism, Institutional Alliances, and Teaching Psychoanalysis: Psychoanalytic and Psycho-Social Studies in the 
United Kingdom. Journal for the Psychoanalysis of Culture and Society 7 (2), pp. 322-328.

Hollway, W. and Jefferson, T. (2002). Heterosexual Relating, Unconscious Intersubjectivity, and Fear of Crime. Journal for the Psychoanalysis of Culture and Society 7 (2), pp. 196-201.

Stopford, A. (2007). Psychoanalysis and Interraciality: Asking Different Questions. Psychoanalysis, Culture and Society 12 (3), pp. 205-225.

International Journal of Critical Psychology 10 (2004). Psycho-Social Research.

Lynne Layton 